\title{
Dural arteriovenous fistulas as a cause of intracranial hypertension due to impairment of cranial venous outflow
}

\author{
Christophe Cognard, Alfredo Casasco, Metin Toevi, Emmanuel Houdart, Jacques Chiras,
} Jean-Jacques Merland

\begin{abstract}
Objectives-A retrospective study was carried out on 13 patients with intracranial dural arteriovenous fistulas (DAVFs) who presented with isolated or associated signs of intracranial hypertension.

Methods-Nine patients presented with symptoms of intracranial hypertension at the time of diagnosis. Ocular fundoscopy available in 12 patients showed bilateral papilloedema in eight and optic disk atrophy in four. Clinical evolution was particularly noticeable in five patients because of chronic (two patients) or acute (after lumbar shunting or puncture: three patients, one death) tonsillar herniation.
\end{abstract}

Results-Two patients had a type I fistula (drainage into a sinus, with a normal antegrade flow direction). The remaining 11 had type II fistulas (drainage into a sinus, with abnormal retrograde venous drainage into sinuses or cortical veins). Stenosis or thrombosis of the sinus(es) distal to the fistula was present in five patients. The cerebral venous drainage was abnormal in all patients.

Conclusion-Type II (and some type I) DAVFs may present as isolated intracranial hypertension mimicking benign intracranial hypertension. Normal cerebral angiography should be added as a fifth criterion of benign intracranial hypertension. The cerebral venous drainage pattern must be carefully studied by contralateral carotid and vertebral artery injections to correctly evaluate the impairment of the cerebral venous outflow. Lumbar CSF diversion (puncture or shunting) may induce acute tonsillar herniation and should be avoided absolutely. DAVF may induce intracranial hypertension, which has a poor long term prognosis and may lead to an important loss of visual acuity and chronic tonsillar herniation. Consequently, patients with intracranial hypertension must be treated, even agressively, to obliterate the fistula or at least to reduce the arterial flow and to restore a normal cerebral venous drainage. The endovascular treatment may associate arterial or transvenous embolisation and lor surgery. Patients in whom the fistula is not obliterated after an endovascular therapeutic procedure, need continous clinical and angiographical follow up.

(F Neurol Neurosurg Psychiatry 1998;65:308-316)
Keywords: arteriovenous fistula; benign intracranial hypertension; dural fistula; endovascular treament; embolisation; intracranial hypertension

Benign intracranial hypertension (pseudotumor cerebri) is defined according to the criteria of Johnston and Paterson, ${ }^{12}$ as signs and symptoms of raised intracranial pressure; the CSF pressure is raised, but has normal composition. Neurological examination gives normal results. Neuroradiological studies are normal, showing normal ventricular size and the absence of a mass effect. According to Johnston et al, ${ }^{3}$ pseudotumor syndrome may be separated into one group of primary pseudotumor syndrome without benign intracranial hypertension or with a recognised precipitating cause, and a second group of secondary pseudotumor syndrome in which the underlying mechanism is either impairment of the cerebral venous drainage, or alterations in the composition of the CSF. We report a retrospective study of 13 patients with intracranial dural arteriovenous fistula presenting with isolated or associated signs of intracranial hypertension.

\section{Methods}

Thirteen patients with intracranial dural arteriovenous fistulas (DAVFs) and presenting with signs of intracranial hypertension were studied. There were seven men and six women with ages ranging from 23 to 70 (mean 50) years. Characteristics of patients are given in table 1. Twelve of these patients have been included in a recent publication ${ }^{4}$ concerning clinical and angiographic correlation in 205 patients with cerebral DAVFs. For 120 patients in that study, the time period for follow up ranged from 6 months to 23 years (mean 52 months), allowing us to relate the clinical evolution in each patient to the corresponding venous pattern. Our study resulted in a revised classification of the venous drainage (table 2). In the present study, one patient (13) was not included in our earlier publication.

Different points were particularly analysed in these 13 patients:

Clinical features - The first clinical symptoms were noted. Symptoms of intracranial hypertension were noted but not in detail, as they often were not sufficiently described in the clinical report. Only one of our patients had a complete CSF study. Consequently, we were not able to analyse either the CSF pressure or the composition. The of onset of symptoms of 


\begin{tabular}{|c|c|c|c|c|c|c|c|}
\hline $\begin{array}{l}\text { Case } \\
\text { No }\end{array}$ & First symptoms & IIH Symptoms & $\begin{array}{l}\text { IIH Sp/onset } \\
\text { (y) }\end{array}$ & Type & Location & $\begin{array}{l}\text { Drainage of the fistula } \\
\text { with reflux in: }\end{array}$ & Sinus anomalies \\
\hline 1 & $\mathrm{IIH}$ & Headache Visual obscurations & 0 & IIa & SSS & SSS, left TS & Right TS thrombosis \\
\hline 2 & Tinnitus, IH & Visual acuity loss Papilloedema & 0 & I & Right TS & No Reflux & Absence of left TS \\
\hline 3 & $\mathrm{IH}$ & $\begin{array}{l}\text { Headache Visual obscurations } \\
\text { Visual acuity loss }\end{array}$ & 0 & $\mathrm{IIa}+\mathrm{b}$ & Right TS & $\begin{array}{l}\text { Left TS, SS, cortical } \\
\text { veins }\end{array}$ & $\begin{array}{l}\text { Thrombosis of right TS and } \\
\text { SSS, straight stenosis of left TS }\end{array}$ \\
\hline 4 & $\mathrm{IH}$ & $\begin{array}{l}\text { Headache Visual acuity loss } \\
\text { Papilloedema }\end{array}$ & 0 & $\mathrm{IIa}+\mathrm{b}$ & Right TS & Left TS & $\begin{array}{l}\text { Thrombosis of SSS posterior } \\
\text { third, stenosis of left TS }\end{array}$ \\
\hline 5 & Tinnitus & $\begin{array}{l}\text { Headache Visual acuity loss } \\
\text { Papilloedema }\end{array}$ & 4 & IIa & Torcular & Both TS, SSS & No \\
\hline 6 & $\mathrm{IH}$ & $\begin{array}{l}\text { Headache Visual acuity loss } \\
\text { Papilloedema }\end{array}$ & 0 & $\mathrm{I}$ & $\begin{array}{l}\text { Both TS and } \\
\text { torcular }\end{array}$ & No reflux & No \\
\hline 7 & $\mathrm{IH}$ & $\begin{array}{l}\text { Visual obscurations } \\
\text { Papilloedema }\end{array}$ & 0 & $\mathrm{IIb}$ & Right TS & Cortical veins, SSS & $\begin{array}{l}\text { Right TS stenosis up and } \\
\text { downstream }\end{array}$ \\
\hline 8 & Tinnitus, IH & $\begin{array}{l}\text { Headache VIth nerve palsy } \\
\text { Papilloedema }\end{array}$ & 0 & $\mathrm{IIa}+\mathrm{b}$ & Left TS & Right TS, SSS & No \\
\hline 9 & Seizure & Visual acuity loss Optic atrophy & 9 & $\mathrm{IIa}+\mathrm{b}$ & Torcular & SSS, cortical veins & Stenosis of both TS \\
\hline 10 & $\begin{array}{l}\text { Frontal superficial } \\
\text { veins dilatation }\end{array}$ & Visual acuity loss Optic atrophy & 13 & IIa & SSS & Both TS, SS, ISS & Straight stenosis of both TS \\
\hline 11 & Tinnitus, IH & Visual acuity loss Optic atrophy & 0 & IIa & Right TS & SSS, left TS & Stenosis of right TS \\
\hline 12 & $\mathrm{IH}$ & $\begin{array}{l}\text { Diplopia Visual acuity loss } \\
\text { Papilloedema }\end{array}$ & 0 & IIa & Left TS & SSS, right TS & Left TS thrombosis \\
\hline 13 & Tinnitus & $\begin{array}{l}\text { Headache Visual obscurations } \\
\text { Papilloedema }\end{array}$ & 0.5 & -IIa-IIa-IIb & $\begin{array}{l}\text { Left TSTorcular } \\
\text { Cavernous sinus }\end{array}$ & $\begin{array}{l}\text { Right TS SSS vein of } \\
\text { Trolar }\end{array}$ & No \\
\hline
\end{tabular}

intracranial hypertension in relation to diagnosis was analysed.

Angiographic features - Side and location of the shunt was noted. Each patient was classified according to the revised classification of Djindjian and Merland depending on the type of venous drainage (table 2). The venous drainage of the fistulas and particularly refluxes into the main sinuses were analysed in detail. Anomalies of the main sinuses were noted and classified as either thrombosed, stenosed, or hypoplastic. The cerebral venous drainage pattern was analysed.

\section{Results}

CLINICAL SYMPTOMS

The first encountered symptoms were those of intracranial hypertension in nine patients (isolated in seven patients and associated with tinnitus in two), tinnitus (two patients), seizure (one patient), and dilatation of superficial frontal veins (one patient). In the four patients without symptoms of intracranial hypertension at the time of the diagnosis, these symptoms appeared from 6 months to 13 years later.

In the 13 patients, symptoms of intracranial hypertension consisted of headache (seven patients), transient visual obscurations (four patients), decreased visual acuity (nine patients), and diplopia due to VIth nerve palsy (two patients). Ocular fundoscopic examination was available in 12 patients, showing bilateral papilloedema (eight patients) and optic disk atrophy ( four patients).

Table 2 Revised classification of Djinjian and Merland

Type I: DAVF draining into a sinus, with a normal antegrade flow direction

Type II: DAVF draining into a sinus. Insufficient antegrade venous drainage and reflux. The insufficiency of the venous drainage may be due to stenosis or occlusion of the sinus draining a moderate flow rate DAVF, or to a very high flow rate DAVF which cannot be drained by a normal or even enlarged sinus. Depending on the retrograde venous drainage, three subtypes are distinguished:

Type IIa: retrograde venous drainage into sinus(es) only

Type IIb: retrograde venous drainage into cortical vein(s) only

Type IIa+b: retrograde venous drainage into sinus(es) and cortical vein(s)

Type III: DAVFs draining directly into a cortical vein without venous ectasia

Type IV: DAVFs draining into a cortical vein with a venous ectasia $>5 \mathrm{~mm}$ in diameter and three times larger than the diameter of the draining vein.

Type V: DAVFs (intracranial) draining into spinal perimedullary veins
Clinical follow up

Ten patients have been followed up for 2-19 (mean 7.5) years. Three patients have been followed up clinically and angiographically only for six months after the endovascular treatment.

\section{ANGIOGRAPHIC FEATURES}

Location and side are detailed in table 1.

\section{Type of venous drainage}

Classification according to the revised version of Djindjian and Merland is shown in table 1. There were two patients with type I fistula; in patient 2 the angiography showed a high flow type I fistula in the right transverse sinus (TS) with a controlateral hypoplastic sinus; patient 6 had a bilateral type I fistula in both TS and torcular. In both patients, antegrade drainage into the ipsilateral jugular vein was seen. The remaining 11 patients (one with three fistulas) had type II fistulas; eight were type IIa, two were type IIb, and 3 were type IIa+b. Venous drainage of fistulas was as follows: reflux into the superior sagittal sinus (SSS) (five patients), into the controlateral TS (six patients), into the inferior sagittal sinus (ISS) (one patient), into the straight sinus (SS) (two patients), and into cortical veins (four patients).

\section{Anomalies of the sinuses}

Only in four patients were the main sinuses considered as normal. In the others we noted hypoplastic contralateral TS (case 2), stenosed parent sinus downstream or upstream of the shunt (cases 8,11 , and 12), and thrombosis or irregular stenosis of the other main sinuses distant from the shunt (five patients).

Cerebral venous drainage was abnormal in all patients with prolongation of both parenchymal phase and venous outflow (fig 1 , table $1)$. Venous drainage through the SSS and TS was seen in five patients, and through the sphenoparietal sinus, cavernous sinus, and superior ophthalmic vein in seven patients. Additional meningeal or transdiploic venous drainage was found in six patients. 
Table 1 continued

\begin{tabular}{|c|c|c|}
\hline Patterns of cerebral venous drainage & $\begin{array}{l}\text { Follow up } \\
\text { (y) }\end{array}$ & Complications \\
\hline $\begin{array}{l}\text { Extremely prolonged, via SPS, sphenoparietal S, } \\
\text { SOV, meningeal veins }\end{array}$ & 15 & Chronic tonsilar herniation \\
\hline Prolonged via SSS and right TS & 1 & \\
\hline $\begin{array}{l}\text { Extremely prolonged, via cavernous sinus and } \\
\text { meningeal veins }\end{array}$ & 3 & $\begin{array}{l}\text { Acute tonsilar herniation (coma) } \\
\text { after lumboperitoneal shunting }\end{array}$ \\
\hline $\begin{array}{l}\text { Prolonged via diploic and facial superficial veins, } \\
\text { cavernous S, SOV }\end{array}$ & 0.5 & \\
\hline Prolonged via SSS, SPS, cavernous S & 6 & \\
\hline Prolonged, via SSS, SS, both TS & 1 & \\
\hline Prolonged, via SSS, Left TS & 19 & \\
\hline Prolonged, via SSS, rigth TS & 2 & \\
\hline Prolonged SSS, sphenoparietal S, cavernous S & 23 & \\
\hline $\begin{array}{l}\text { Extremely prolonged, via cav } \mathrm{S} \text { and meningeal } \\
\text { veins }\end{array}$ & 16 & Chronic tonsilar herniation \\
\hline $\begin{array}{l}\text { Extremely prolonged, via cav } \mathrm{S} \text { and meningeal } \\
\text { veins }\end{array}$ & 8 & $\begin{array}{l}\text { Acute tonsilar herniation (death) } \\
\text { after lumboperitoneal shunting }\end{array}$ \\
\hline Prolonged via SSS and right TS & 3 & \\
\hline $\begin{array}{l}\text { Prolonged via straight } S \text {, right } T S \text {, meningeal } \\
\text { veins }\end{array}$ & 0.5 & $\begin{array}{l}\text { Acute confusion after lumbar } \\
\text { puncture regressive after } \\
\text { embolisation }\end{array}$ \\
\hline
\end{tabular}

ASSOCIATED CLINICAL PHENOMENA

In five patients there were clinical complications from chronic or acute tonsilar herniation

In patient 10 (figure 2), an SSS fistula evolving for 16 years produced an intracranial hypertension leading to an asymptomatic chronic tonsillar herniation which was disclosed on MRI. The fistula drained into the TS, SS, and ISS. Both TS were stenosed. The cerebral venous drainage through transcerebral and meningeal veins was extremely prolonged.

Patient 1 (figure 3), with an SSS high flow fistula, has been followed up for 15 years. The fistula drained into the SSS and left TS. The right TS was thrombosed. The encephalon drained into the superior petrosal sinuses, sphenoparietal sinuses, and superior ophtalmic veins. On MRI a tonsillar herniation was found as well as hydromyelia; both were asymptomatic.

Patient 11 had a very high flow fistula of the right TS. Nine years after diagnosis, the patient presented with a decrease of visual acuity. The fistula drained into the left TS and SSS. The cerebral venous drainage through the cavernous sinuses and meningeal veins was extremely prolonged. It was impossible to reduce the flow enough to obtain a clinical improvement by endovascular means. A lumboperitoneal shunt was performed. Immediately after the shunting procedure, the patient had a general seizure and died from respiratory problems due to an acute tonsillar herniation.

Patient 3 (figure 4) had a right TS fistula. For four years the patient had had a headache and impairment of visual acuity. The fistula drained into the left TS, SS, and cortical veins. Both TS were thrombosed and the cerebral venous drainage through the cavernous sinuses and meningeal veins was prolonged. Due to inefficient results of endovascular treatment together with a further decrease of visual acuity, a lumboperitoneal shunting was performed, instantly leading to coma, which was reversed on removal of the shunt.
Patient 13, a 60 year old man had a left sided tinnitus, increasing headache, and visual obscurations. On clinical examination a left sided retroauricular bruit was audible. Funduscopic examination disclosed bilateral papilloedema. Brain CT performed after contrast administration was normal. After a lumbar puncture the patient acutely deteriorated with deep confusion, hallucinations, and mild aphasia. Cerebral angiography disclosed a complex dural fistula; a left TS type IIa+b fistula draining backward to the right TS and left cortical veins (probably responsible for the acute aphasia), a right TS and torcular type IIa fistula draining into the SSS, and a right paracavernous fistula draining into cortical veins. The cerebral venous drainage, mainly through the deep venous system and transmeningeal veins, was extremely prolonged. An endovascular treatment using coils to occlude the left TS was performed through the left jugular vein. Additionally two endovascular procedures were performed, by which most of the meningeal branches of both external carotid arteries were embolised using glue (Histoacryl). One week after these procedures, the patient was fully conscious, without neurological deficits.

\section{Discussion}

Pseudotumor syndrome was initially described by Quincke in 1897 under the term "serous meningitis" as a concept of raised intracranial pressure due to impaired CSF circulation secondary to several aetiological factors. ${ }^{5}$ The term "benign intracranial hypertension", was introduced by Foley in $1955 .{ }^{6}$ The various terms associated with isolated intracranial hypertension reflect the extreme heterogeneity of the aetiological factors, thus making benign intracranial hypertension a very miscellaneous group..$^{7-11}$ In 1974, Johnston and Paterson asserted that "error in diagnosis of benign intracranial hypertension due to overlooking other causes of raised intracranial pressure are few if the appropriate criteria are observed". ${ }^{2}$ In 1991, Johnston et al proposed a classification of "pseudotumor syndromes". ${ }^{3}$ Group IA corresponds to "true benign intracranial hypertension" with no recognisable cause. These idiopathic benign intracranial hypertensions are known to occur usually in women of reproductive age, most often overweight or obese, and often displaying menstrual irregularities. ${ }^{189}{ }^{12-16}$ Group IB of Johnston et al corresponds to "primary pseudotumor syndrome" with recognised precipitating cause. Group II is secondary pseudotumor syndrome due to either impairment of cerebral venous outflow or altered CSF composition. Impairment of cerebral venous outflow can produce intracranial hypertension either by venous obstruction, as in cerebral venous thrombosis (CVT), or by hypertension (dural fistulas, intracranial arteriovenous malformations).

Several authors have described cerebral venous thrombosis, mimicking benign intracranial hypertension. ${ }^{81217-20}$ For these reasons, Rousseaux et $a l^{20}$ proposed to add a fifth crite- 

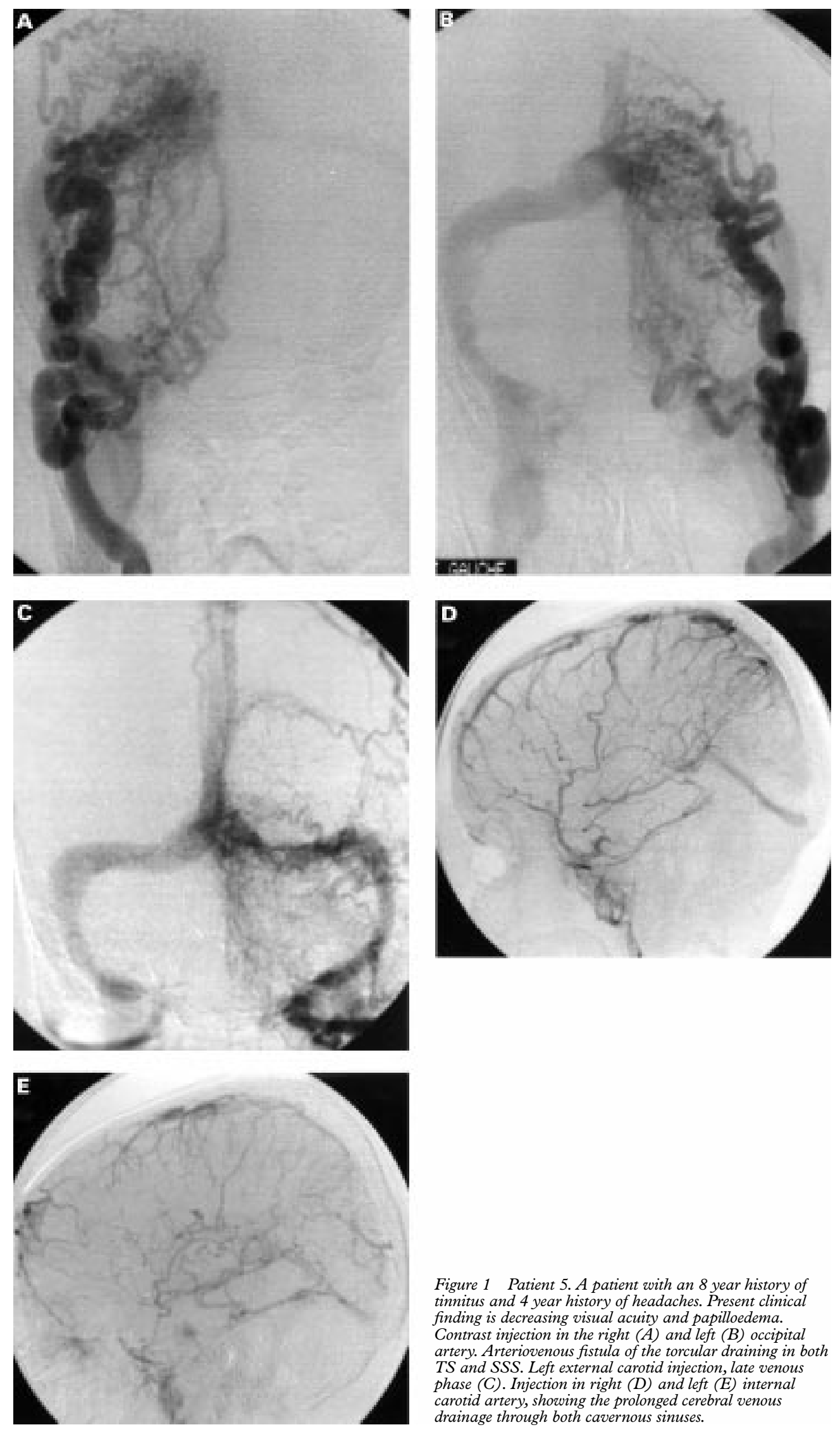

Figure 1 Patient 5. A patient with an 8 year history of tinnitus and 4 year history of headaches. Present clinical finding is decreasing visual acuity and papilloedema. Contrast injection in the right $(A)$ and left $(B)$ occipital artery. Arteriovenous fistula of the torcular draining in both TS and SSS. Left external carotid injection, late venous phase $(C)$. Injection in right $(D)$ and left $(E)$ internal carotid artery, showing the prolonged cerebral venous drainage through both cavernous sinuses.

rion to those of Johnston and Paterson; "absence of cerebral venous thrombosis proved by cerebral angiography." 

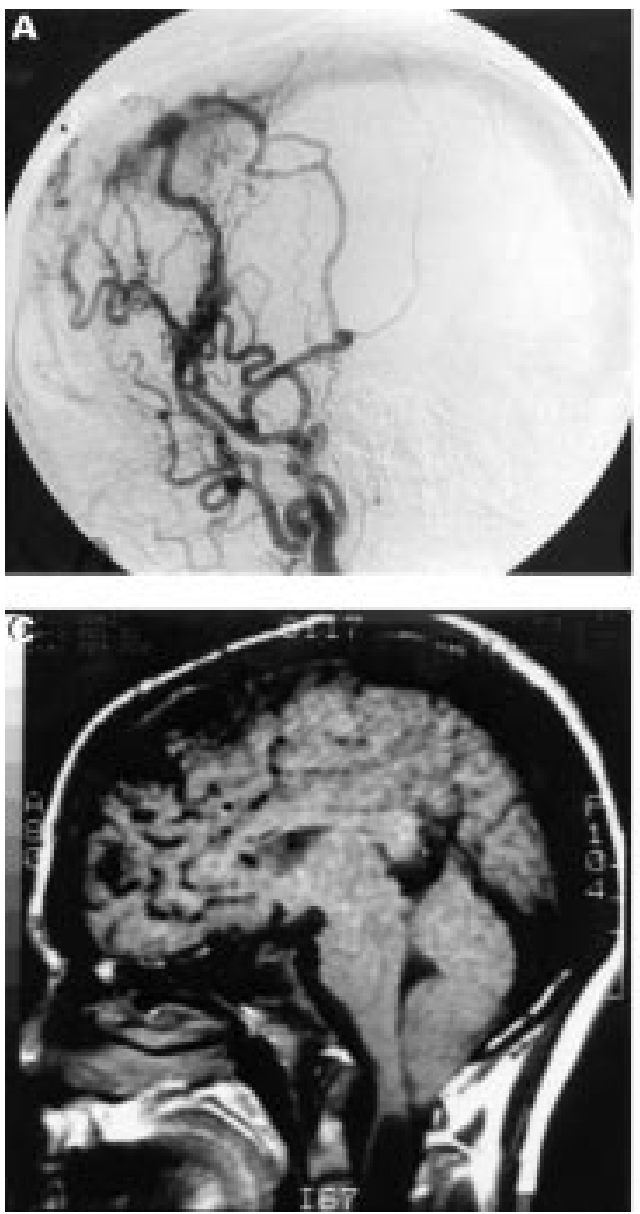

DURAL FISTULAS MAY PRODUCE ISOLATED INTRACRANIAL HYPERTENSION MIMICKING BENIGN INTRACRANIAL HYPERTENSION

Symptoms of intracranial hypertension have often been described as symptoms of DAVFs. ${ }^{21-27}$ The problem is to be aware of the possibility of a dural fistula when the patient presents with isolated intracranial hypertension. In fact, in the present study, in nine patients, the first presentation of the DAVF was by symptoms of intracranial hypertension (seven isolated, two associated with tinnitus). In the four remaining patients, the first symptoms of the DAVF were tinnitus in two patients, dilatation of superficial frontal veins in one, and seizures in one. In these four patients, symptoms of intracranial hypertension appeared with long term evolution, from 1 to 13 years after the first onset of symptoms. patient 13 illustrates the difficulty in diagnosing a dural fistula as the cause of intracranial hypertension, even in the presence of tinnitus, which is its most characteristic symptom. Furthermore, tinnitus has been described as a common sign of increased intracranial pressure. ${ }^{1}{ }^{1628}$ Tinnitus can be attributed to the intracranial hypertension and may therefore lead to the wrong diagnosis. Brain CT and MRI are often normal in dural fistulas without cortical venous drainage. Lumbar puncture is of considerable interest in the exploration of isolated intracranial hypertension, but may be very dangerous in the presence of a dural fistula. Thus, before performing a lumbar

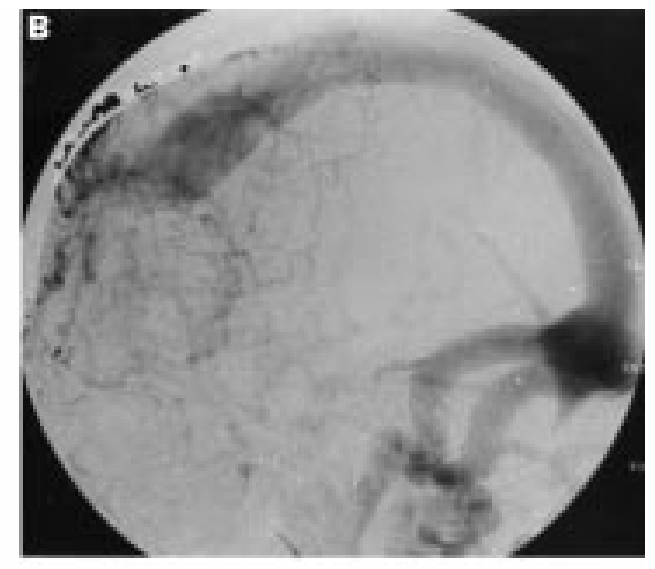

Figure 2 Patient 10. The patient presented in 1975 with dilatation of frontal superficial veins. Angiography at that time disclosed a type II A AVF of the SSS. In 1988, there was bilateral impairment of visual acuity. A repeated right sided ECA angiography $(A)$ shows immensely dilated pedicles to the fistula. Venous phase (B): drainage into the dilated SSS, both TS and straight sinus. Sagittal T1 weighted MRI (C) shows chronic tonsillar herniation and syringomyelia.

puncture in patients with isolated intracranial hypertension, attempts should be made to try to exclude the existence of a dural fistula. An external carotid artery Doppler examination searching for an asymmetric velocity could be helpful, and if abnormal, followed by cerebral angiography. This is in agreement with the proposition by Rousseaux et $a l^{20}$ to add a normal cerebral angiography as the fifth criterion of benign intracranial hypertension. The accuracy of MR angiography to disclose DAVFs remains to be established.

LONG TERM EVOLUTION OF DURAL FISTULAS MAY PRODUCE DEVASTATING INTRACRANIAL HYPERTENSION

Intracranial hypertension caused by cerebral venous thrombosis most often rapidly improves if the thrombosed sinus(es) is recanalised. ${ }^{17} \mathrm{On}$ the other hand, symptoms of intracranial hypertension often worsen in the long term evolution of dural fistulas. The persistent arterialisation of the main dural sinuses for many years, in untreated or incompletely treated fistulas, is responsible for devastating symptoms of intracranial hypertension. The consequences may be tragic, with continuous loss of visual acuity leading to complete blindness, or with chronic or acute tonsilar herniation that may be lethal.

It is necessary to define the angiographic features of DAVFs to allow the prediction of later occurrence of intracranial hypertension. 

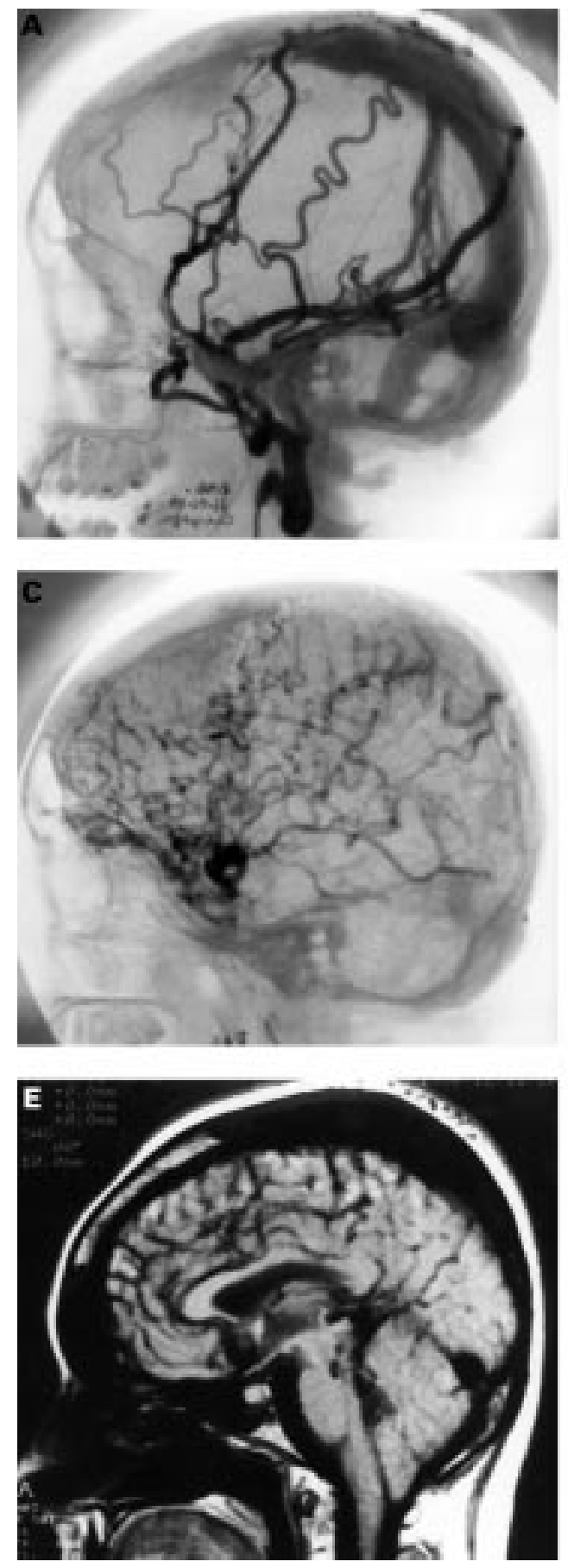

Type of fistula

In our previous study, ${ }^{4}$ intracranial hypertension was present in 10 of 55 patients with type II fistulas $(20 \%)$ and in two of 84 patients with type I fistulas.

Type I DAVFs are always considered as benign but in two of our patients it produced impairment of the cerebral venous drainage and symptoms of intracranial hypertension: in patient 2 , the high flow fistula was located on the only functional transverse sinus (contralateral hypoplastic transverse sinus), in patient 6 , the fistula was bilateral (located on both transverse sinus). In these patients, despite a normal antegrade drainage of the fistula, the cerebral venous drainage was
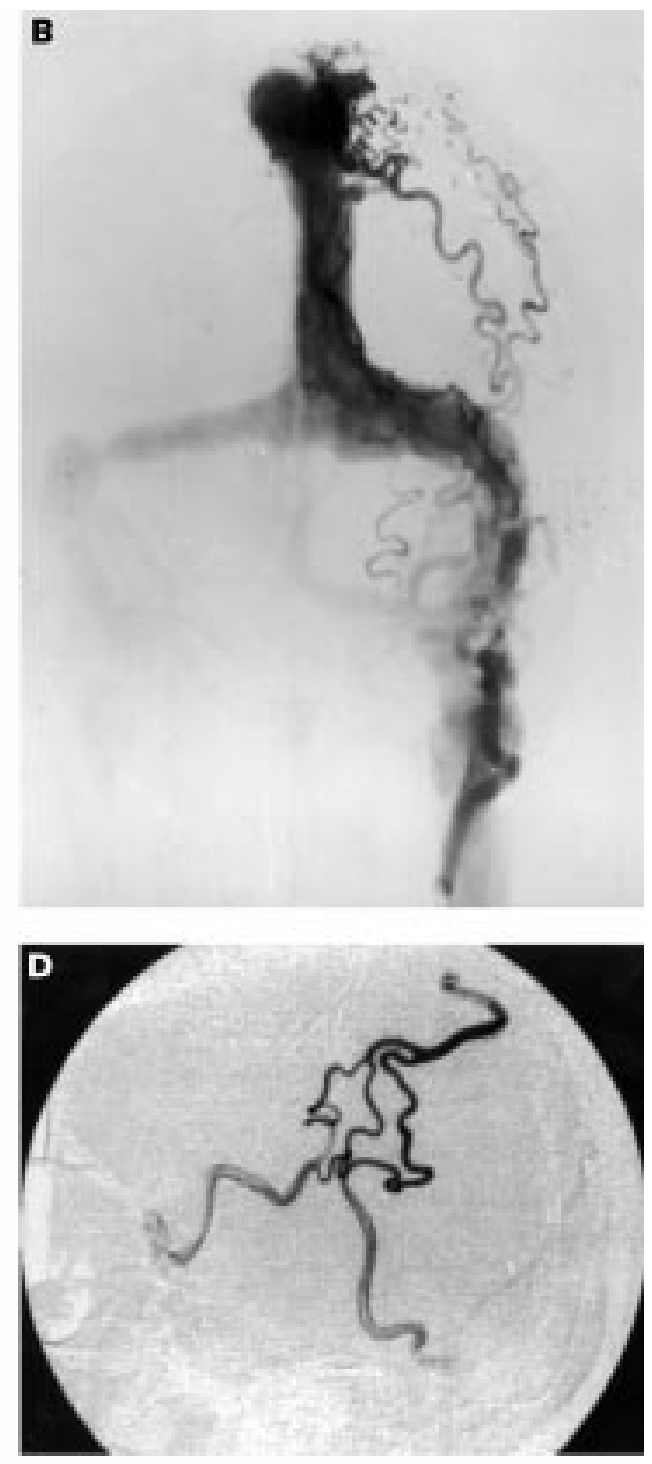

Figure 3 Patient 1. Type II A AVF of the SSS. The patient presented with headache and visual obscurations. Right $E C A$ angiogram $(A)$ shows dilated feeding arteries. Left $E C A$ angiogram late venous phase $(B)$ drainage through the left TS. The right TS is occluded. Right intracranial artery, venous return $(C)$ prolonged venous drainage through cavernous sinuses and superior ophtalmic vein. During an attempt to occlude the SSS by a transvenous approach a microcatheterisation and contrast injection in cortical veins was performed (D), showing backward drainage. Sagittal T1 weighted MRI (E) shows tonsillar herniation.

impaired, which induced a raised intracranial pressure.

Type II DAVFs drain into a sinus with insufficient antegrade venous drainage and abnormal retrograde venous drainage into sinuses or cortical veins. Insufficiency of the fistula venous drainage and reflux may be due to moderate flow rate DAVF in cases of stenosis or occlusion of the sinus. On the other hand, very high flow rate DAVF may create similar insufficiency of the venous drainage despite a normal or even enlarged sinus. In our 13 type II fistulas (in 11 patients), we found a retrograde drainage and arterialisation of the SSS in five patients, of the ISS in one, of the SS in two, and of the controlateral TS in six. 
A

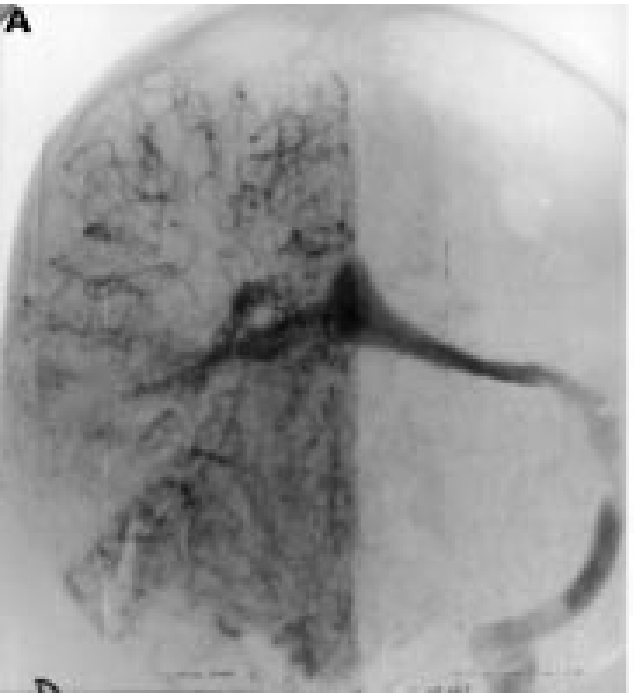

B

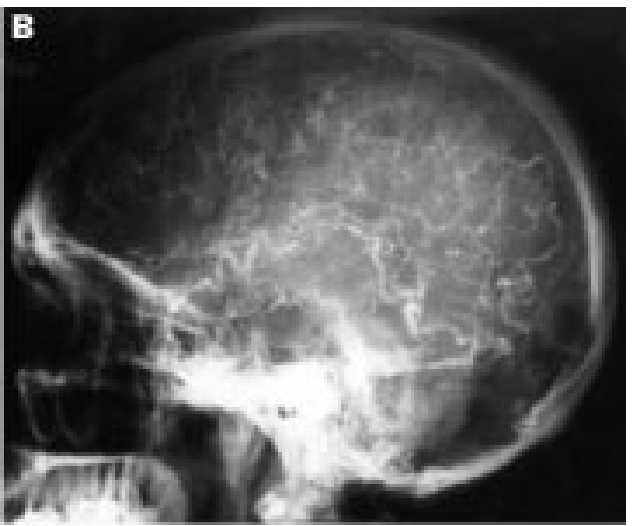

Figure 4 Case 3. The patient presented in 1982 with headache, visual obscurations, and visual loss. Two sessions of arterial embolisation using particles resulted in a transient clinical improvement. In 1986, a lumboperitoneal shunting resulted in deep coma, which reversed after removing the shunt. Right common carotid artery angiogram $(A)$ venous return of the type IIa+b right TS AVF. Venous drainage through the right TS occluded downstream backwards to the left TS (very narrowed). Left intracranial artery angiogram (B) shows the prolonged venous drainage. There is absence of opacification of SSS, both TS, and straight sinus.

Anomalies of the sinuses

The main factor which is associated with the arterial reflux into sinuses and contributes to compromise the cerebral venous drainage is an anomaly of the sinus distal to the fistula. This feature was present in five of our patients. The relation between sinus thrombosis and DAVFs has been described by others. Most authors agree that DAVFs arise from sinus thrombosis. $^{71030-34}$ Sinus lesions secondary to initial thrombosis may be spread not only to the parent sinus but also to others. Also, the fistula itself and arterialisation of sinuses may induce secondary lesions to the sinus wall. ${ }^{4} 26$ 29-37 Thus three main factors are of importance in modifying the cerebral drainage: arterialisation of the sinus due to the fistula, sinus lesions due to the initial thrombophlebitis, and secondary sinus wall lesions due to the arterial flow. The best witness of these haemodynamic or thrombotic changes of the venous pathways is study of the cerebral venous drainage.

\section{Cerebral venous drainage}

Angiographic examination, with contrast injection into the contralateral internal carotid and vertebral arteries, is indispensible in the study of the cerebral venous drainage. In our patients, the cerebral venous drainage was always abnormal with prolongation of parenchymal phase venous outflow. The venous drainage was through the SSS and TS in only five of the 13 patients. The main pathways for venous outflow were cavernous sinuses (seven patients) and meningeal or transdiploic drainage (six patients).

\section{Management implications}

In type II dural fistulas, it is necessary to precisely evaluate the impairment of the venous outflow and as a consequence of this, the venous hypertension. In our opinion, type II fistulas should be defined as fistulas with abnormal cerebral venous drainage predisposing both symptoms of intracranial hypertension and complications, taking into account not only the venous drainage of fistulas but also any existing sinus anomaly. The cerebral venous drainage pattern has to be followed angiographically in the long term evolution of type II fistulas. Any changes of the venous drainage pattern have to be related to the neurological symptomatology. The venous hypertension may augment, either by increased flow rate or by decreased venous outflow. If there is increased flow rate, this has to be evaluated often (once a year) by flow velocity control, using Doppler. An important increase in the flow velocity may lead to increased venous reflux into the main sinuses which in turn can induce an impairment of the cerebral venous drainage. Indications of increasing flow velocity by Doppler should lead to a repeated angiographic examination.

\section{PATHOPHYSIOLOGY}

Kuhner et al and Tomsick et al have postulated that the mechanism of intracranial hypertension in dural fistulas is the increased dural sinus pressure, resulting in a secondary diminution of the CSF absorption. ${ }^{23}{ }^{38}$ Lamas et al have shown that the increased pressure in the SSS is directly related to the flow rate inside the fistula; in one patient, decreasing flow rate by embolisation, they normalised the pressure inside the SSS. ${ }^{39}$ The most likely hypothesis to explain intracranial hypertension in type II DAVFs is that the increased pressure in the SSS produces a reduction in CSF resorption. Resorption of CSF is a passive phenomenon roughly depending on the following equation:

$\mathrm{CSF}$ resorption $=\mathrm{CSF}$ pressure $-\mathrm{SSS}$ pressure/ resistance of outflow

Thus it follows that an increase in SSS pressure lowers the CSF resorption which in turn leads to increased intracranial pressure. Fur- 
thermore, in accordance with the MonroeKellie rule, the increased SSS pressure produces a rise in cortical venous pressure. The increase in intracranial pressure restores the gradient across the villi, thereby balancing the increased SSS pressure. Janny et al have postulated that dysfunction of the CSF resorption is present in benign as well as in some nonbenign forms of intracranial hypertension, suggesting the same mechanism in both conditions. ${ }^{18}$ In their study, the pressure gradient between CSF and SSS was reversed or nullified in patients with sinus hypertension or sinus obstruction, whereas CSF resistance of outflow was found to be normal. In cerebral venous thrombosis as well as in dural arteriovenous fistulas, the impairment of the venous outflow is responsible for the increase in SSS pressure.

LUMBAR PUNCTURE OR SHUNTING IS DANGEROUS Five of the 13 patients in the present study were particularly illustrative by showing the consequences of the pressure gradient between SSS and CSF. The increased intracranial pressure leads to an altered equilibrium, with increased CSF pressure against the increased pressure into the arterialised sinuses. This alteration of the equilibrium may be modified, either by arterial embolisation for better, or by lumbar shunting or puncture for worse.

In two of our patients, asymptomatic chronic tonsillar herniation improved after arterial embolisation. In each of these patients chronic tonsillar herniation was found after a follow up period of 15 and 16 years respectively. After arterial endovascular treatment, the lowered arterial and thus sinus pressure resulted in decreased intracranial pressure.

In three patients, on the other hand, we found acute clinical deterioration. Two of these (patients 3 and 11) had high flow fistulas followed up for 3 and 8 years respectively. Arterial embolisations performed resulted in a temporary clinical improvement. Lumbar shunting was indicated because of acute loss of visual acuity. After the shunting procedure, patient 11 died from respiratory problems due to acute tonsillar herniation. Patient 3 became comatose shortly after shunting. However, after removing the shunt, the patient regained consciousness. Patient 13 acutely deteriorated with deep confusion, hallucinations and mild aphasia after a diagnostic lumbar puncture. One week after three sessions of endovascular treatment, the patient was asymptomatic.

We think that the mechanism explaining the deterioration in these three patients is that the rapid decrease in CSF pressure that follows a lumbar shunting or puncture induces an acute differential pressure and leads to herniation. Therefore it must be kept in mind that DAVFs can induce potentially devastating intracranial hypertension. Lumbar CSF diversion should be absolutely avoided in these patients.

THERAPEUTIC ATTITUDE

The treatment of type II fistulas has previously been discussed. ${ }^{4}$ As it seems that retrograde drainage produces intracranial hypertension in
$20 \%$ of the patients, type II fistulas consequently must be considered as potentially dangerous. Asymptomatic patients have to be examined repeatedly (once a year) with neurological examination including ophthalmoscopy, and Doppler studies. We think that MRI could play a part as a method of screening patients with benign intracranial hypertension. However, our own experience in this field is too limited to draw any firm conclusions. MR angiography will probably be a reliable examination in the future. Nevertheless, its capacity to precisely analyse the fistula venous drainage and the cerebral venous drainage will remain certainly less accurate than selective or hyperselective angiography. Whatever the method, the competition of the venous drainage of the fistula and of the brain needs to be clearly analysed to indicate the therapeutic decisions.

Due to the poor prognosis of longstanding intracranial hypertension, patients with intracranial hypertension have to be treated (even aggressively). The aim for the treatment should not be an anatomical cure if it is risky, but instead the flow rate inside the shunt should be decreased, thereby reducing the pressure inside the sinus.

Arterial embolisations using particles is considered to be the treatment posing less risks. ${ }^{27324041}$ However, the long term results using this method are disappointing, showing a high degree of arterial recanalisation. Embolisation with glue is often required but may be insufficient in patients with multiple pedicles and large shunts, or where the arterial feeders originate from the internal carotid or vertebral arteries. $^{324142}$ The transvenous approach by retrograde or contralateral catheterisation of the parent sinus and occlusion using coils is considered by several neuroendovascular teams to be the best way to cure these fistulas. ${ }^{49}{ }^{42-45}$ In some patients, catheterisation of the parent sinus is impossible and a surgical approach is required. It may consist of either a surgical embolisation combined procedure by direct puncture and coiling through a burr hole created a few days before or a direct surgical exposure and occlusion of the parent sinus.

\section{Conclusion}

Dural fistulas may produce isolated intracranial hypertension mimicking benign intracranial hypertension. The isolated intracranial hypertension is also difficult to distinguish from benign intracranial hypertension. Thus before performing a lumbar puncture in patients with isolated intracranial hypertension, attempts should be made to exclude the existence of a dural fistula. Dural fistulas produce intracranial hypertension which is associated with a poor long term prognosis. They may often induce an important decrease of visual acuity and may also cause acute deterioration due to acute increases in intracranial pressure which may lead to cerebral herniation. The cerebral venous outflow impairment in type II fistulas has to be carefully studied by cerebral angiography, including examination of contralateral carotid and vertebral arteries. All patients have to be carefully and repetitively 
followed up. Endovascular treatment aiming at reducing the flow rate of the fistula, is in our opinion often required.

1 Johnston I, Paterson A. Benign intracranial hypertension I Diagnosis and prognosis. Brain 1974;97:289-300.

2 Johnston I, Paterson A. Benign intracranial hypertension II CSF pressure and circulation. Brain 1974;97:301-12

3 Johnston I, Hawke S, Halmagyi M, et al. The pseudotumor syndrome: disorder of cerebrospinal fluid circulation causing intracranial hypertension without ventriculomegaly. Arch Neurol 1991;48:740-7.

4 Cognard C, Gobin Y, Pierot L, et al. Cerebral dural arteriovenous fistulas: clinical and angiographic correlation with a revisited classification of venous drainage. Radiology 1994 194:671-80.

5 Quincke H. Uber meningitis serosa und verwandte zustande. Deutsche Zeitschrift für Nervenheikrunde 1897;9: 149-68.

6 Foley J. Benign forms of intracranial hypertension toxic and otitic hydrocephalus. Brain 1955;78:1-41.

7 Convers P, MD Brunon J, Sindou M. Fistules artérioveineuses durales de la fosse postérieure et thrombose du sinus latéral: discussion de leur relations et de leur traitement à propos de deux cas. Neurochirurgie 1986, 32:495-500.

8 Danze F, Rosa A, Mizon J. Hypertension Intracranienne Bénigne. (pseudotumor cerebri): douze cas. Rev Neurol (Paris) 1985;140:37-44

9 Durcan F, Corbett J, Wall M. The incidence of pseudotumor cerebri. Arch Neurol 1988;45:875-7.

10 Handa J, YS Handa H. Venous sinus occlusion with dural arteriovenous malformation of the posterior fossa. Surg Neurol 1975;4:433-7.

11 Nönne M. Uber Fälle von symptomenkomplex "tumor cerebri" mit ausgang in heilung (pseudotumor cerebri). Zeitschrift für Nervenheilkunde 1904;27:169-216.

12 Donaldson J. Pathogenesis of pseudotumor cerebri syndromes. Neurology 1981;31:877-80.

13 Guidetti B, Giuffre R, Gambacorta D. Follow up study of 100 cases of pseudotumor cerebri. Acta Neurochir (Wien) 1968;18:259-67.

14 Rush A. Pseudotumor cerebri: clinical and visual outcome in 63 patients. Mayo Clin Proc 1980;55:541-6.

15 Silberstein S, Marcelis J. Headache associated with changes in intracranial pressure. Headache 1992;32:84-94.

16 Wall $M$, George D. Idiopathic intracranial hypertension: a prospective study of 50 patients. Brain 1991;114:155-80.

17 Ameri A, Bousser M. Cerebral venous thrombosis. Neurol Clin 1992;10:87-111.

18 Janny P, Chazal J, Colnet G, et al. L'hypertension intracranienne bénigne: étude clinique, physiopathologique et nosoenne bénigne: étude clinique, physiopatho

19 Mas JL, Meder J, Meary E, et al. Magnetic resonance imaging in lateral sinus hypoplasia and thrombosis. Stroke 1990 21:1350-6.

20 Rousseaux P, Vieillart A, Scherpereel B, et al. Hypertension intracranienne bénigne ( $17 \mathrm{cas}$ ) et thromboses veineuse cérébrales (49 cas). Etude comparative. Neurochirurgie 1985;31:381-9.

21 Gelwan MJISC, Berenstein A, Pile-Spellman J, Kupersmith MJ. Dural arteriovenous malformations and papilloedema. Neurosurgery 1988;22:1079-84.

22 Kosnik E, Hunt W, Miller C. Dural arteriovenous malformations. $\mathcal{7}$ Neurosurg 1974;40:322-9.

23 Kühner A, Krastel A, Stoll W. Arteriovenous malformation of the transverse dural sinus. F Neurosurg 1974:45:12-19.

24 Lasjaunias P, Chiu M, Brugge KT, et al. Neurological manifestations of intracranial dural arteriovenous malformations. F Neurosurg 1986;64:724-30.
25 Obrador S, Soto M, Silvela J. Clinical syndromes of arteriovenous malformations of the transverse sigmoid sinus. $\mathcal{F}$ Neurol Neurosurg Psychiatry 1975;38:436-51

26 Piton J, Guilleux H, Guibert-Tranier F, et al. Fistules du sinus latéral. F Neuroradiol 1984;11:143-59.

27 Vinuela F, Fox A, Pelz D, et al. Unusual clinical manifestations of dural arteriovenous malformations. $\mathcal{F}$ Neurosurg 1986;64:554-8.

28 Round R, Keane J. The minor symptoms of increased intracranial pressure. 101 patients with benign intracranial hypertension. Neurology 1988;38:1461-4.

29 Cognard C, Houdart E, Casasco A, et al. Long term changes in intracranial dural arteriovenous fistulae leading to worsening in the type of venous drainage. Neuroradiology 1997; 39:59-66.

30 Chaudhary M, Sachdev V, Cho S, et al. Dural arteriovenous malformations of the major venous sinuses: an aquired lesion. AfNR Am f Neuroradiol 1982;3:13-19.

31 Houser O, Baker $\mathrm{H}$, Rhoton A, et al. Intracranial dural arteriovenous malformations. Radiology 1972;105:55-64.

32 Lasjaunias P, Halimi P, Lopez-Ibor L, et al. Traitement endovasculaire des malformations vasculaires durales pures spontanées. Neurochirurgie 1983;30:207-23.

33 Roland J, Bernard C, Bracard S, et al. Microvascularization of the intracranial dura mater. Surg Radiol Anat 1987;9:439.

34 Watanabe A, Takahara Y, Ibuchi Y, et al. Two cases of dural arteriovenous malformation occuring after intracranial surgery. Neuroradiology 1984;26:375-80.

35 Barnwell S, Halbach V, Dowd C, et al. A variant of arteriovenous fistulas within the wall of dural sinuses. F Neurosurg 1991;74:199-204

36 Lalwani A, Dowd C, Halbach VV. Grading venous restrictive disease in patients with dural arterio-venous fistulas of the transverse/sigmoid sinus. $\mathcal{F}$ Neurosurg 1993;79: 11-15.

37 Nishijima M, Takaku A, Endo S, et al. Etiological evaluation of dural arteriovenous malformations of the lateral and sigmoid sinuses based on histopathological examinations. $\mathcal{f}$ Neurosurg 1992;76:600-6.

38 Tomsick T, Tew J, Lukin R. Intracranial arteriovenous malformations with increased intracranial pressure: response to embolization. In: Smith RR, Haerera AF, Russel WF, eds. Vascular malformations and fistulas of the brain. New york: Raven Press, 1982:119-27.

39 Lamas E, Lobato R, Esperza J, et al. Dural posterior fossa AVM producing raised sagittal sinus pressure. case report: f Neurosurg 1977;46:804-10.

40 Fermand M, Reizine D, Melki J, et al. Long term follow up of 43 pure dural arteriovenous fistulas of the lateral sinus. Neuroradiology 1987;29:348-53.

41 Halbach VV, Higashida R, Hieshima G, et al. Dural fistulas involving the transverse and sigmoid sinuses: results of the treatment in 28 patients. Radiology 1987;163:443-7.

42 Halbach VV, Higashida R, Hieshima G, et al. Transvenous embolization of dural fistulas involving the transverse and sigmoid sinuses. AfNR Am f Neuroradiol 1989;10:385-92.

43 Barnwell S, Halbach V, Higashida CD, et al. Dural arteriovenous fistulas involving the inferior petrosal sinus. AfNR Am f Neuroradiol 1990;11:511-6.

44 Gobin Y, Rogopoulos A, Aymard A, et al. Percutaneous transvenous embolization throught the thrombosed sinus in two transverse sinus dural fistulas. AfNR Am f Neuroradiol 1993;14:1102-5.

45 Urtasun F, Biondi A, Casasco A, et al. Cerebral dural arteriovenous fistulas: percutaneous transvenous embolization. Radiology 1996;199:209-17. 